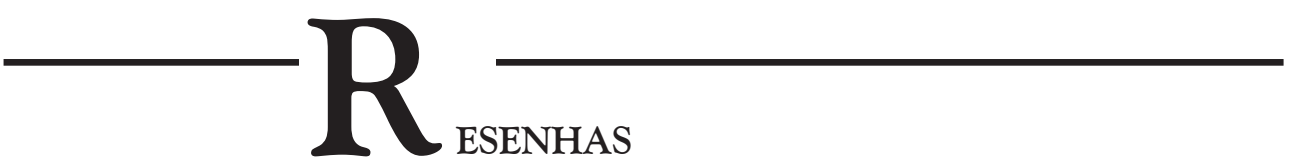

LOPES, Antonio Herculano (org.). Religião e performance ou as performances das religiões brasileiras. Rio de Janeiro: Edições Casa de Rui Barbosa, 2007, 228 p. (Coleção FCRB Aconteceu; 3).

\title{
FESTAS E RITUAIS RELIGIOSOS: A PERFORMANCE COMO PERSPECTIVA DE ANÁLISE
}

\section{Renata de Sá Gonçalves}

O livro organizado por Antonio Herculano Lopes nos mostra a pluralidade da reflexão acadêmica contemporânea acerca dos aspectos rituais das festas e das religiões no Brasil quando o viés analítico é a performance. O livro resulta do "Encontro de Pesquisadores sobre Performance e Religião" realizado na Fundação Casa de Rui Barbosa em outubro de 2003. Fruto de um projeto de Antonio Herculano Lopes e Zeca Ligiéro, ambos ex-alunos de Richard Schechner, diretor de teatro e um dos expoentes da antropologia da performance, o objetivo do encontro era refletir sobre os estudos de performance não como um conceito com contornos precisos mas, ao contrário, como "perspectiva de análise" de fenômenos sociais, destacadamente dos ritos religiosos. Ao promover o debate entre autores de áreas de formação variadas como a história, a antropologia e as artes, Lopes identifica o desafio de lidar com o grau de imprecisão inevitável que o termo performance provoca no âmbito dos estudos acadêmicos. 
A aproximação que a noção de performance propicia entre o teatro e a antropologia percorre a estruturação da maioria dos treze textos organizados nesta coletânea. Os estudos de performance trazem à tona várias possibilidades de arranjos em que, para usar a terminologia do teatro, atores, platéias, cenários, máscaras, ao permitirem o deslocamento de perspectivas e de lugares sociais, possibilitam também, do ponto de vista analítico, o acesso a novos prismas de interpretação das relações sociais.

O livro está dividido em quatro partes. A primeira parte - "Da mistura ibérica à mistura americana" - reúne um conjunto de estudos sobre festas que se entrelaçam pelo viés da mistura de elementos portugueses, africanos e ameríndios ou da "miscigenação cultural que nos marca", como destacado por Lopes (:13). É composta pelos estudos de Rogério Ribas, sobre festas mouriscas nas fontes inquisitoriais portuguesas; de Jacqueline Hermann, que problematiza o sebastianismo afro-caboclo nas ilhas dos Lençóis; de Rubens Alves da Silva, sobre manifestações de congada no sertão de Minas Gerais; e de Maria Laura Cavalcanti, sobre visualidade e imagens do tempo no desfile das escolas de samba do Rio de Janeiro e no festival dos bois-bumbá de Parintins no Amazonas.

$\mathrm{Se}$ os quatro autores reunidos na primeira parte oferecem ao leitor um painel em que se desenham diferentes perspectivas ou representações sobre a miscigenação como elemento central das performances realizadas, fica também em evidência o aspecto temporal como um dos importantes aspectos colocados em perspectiva nos textos reunidos nessa parte. Ribas trata a dimensão temporal por meio da perspectiva etno-histórica propiciada por sua análise da documentação inquisitorial. $O$ historiador enfatiza a identidade cultural mourisca no Portugal quinhentista por sua multiplicidade de festas - privadas, públicas e clandestinas - que a comunidade étnico religiosa celebrava em terras cristãs. $O$ aspecto performativo e, portanto, múltiplo, se mostra central na afirmação de uma identidade mourisca. A historiadora Hermann, por sua vez, percebe no tambor de mina uma rica e complexa modalidade de crença maranhense em D.Sebastião. Um "compósito de perspectivas religiosas" (:47) que permitiu uma variedade de formas assumidas no sebastianismo maranhense. Ao longo dos séculos, dando lugar a uma perspectiva mítica do tempo, a autora identifica uma "teia de enredos" que misturou elementos portugueses, africanos e indígenas (:51).

Ainda na primeira parte do livro, as perspectivas antropológicas da performance e do drama estão presentes nos textos de Rubens da Silva e Maria Laura Cavalcanti. Rubens da Silva foca o drama da Comunidade Arturos, reconhecida como ícone da "tradição" do congado em Minas Gerais, no contexto do Encontro de Congados das Festas de Agosto na cidade de Montes Claros. O antropólogo esteve atento às articulações propiciadas neste evento pela qualidade de seu "movimento continuum" (:66), que vai do ritual ao teatro e vice-versa, bem como da relação do público com a performance estudada (:67), pontos 
destacados por Schechner. No contexto descrito, Silva analisa a "missa conga" como uma performance em que estão presentes mediações entre grupos sociais diversos como a Secretaria Municipal de Cultura e a Igreja Católica no processo de legitimação dos Arturos. Desse modo, o autor destaca a celebração congadeira no contexto de uma missa carismática como performance propiciadora de deslocamentos dos usos mais corriqueiros do espaço da Igreja Católica e do próprio desempenho dos Arturos. Cavalcanti, por sua vez, apresenta ao leitor a análise comparativa de duas importantes e expressivas festas - o carnaval carioca e o boi-bumbá de Parintins. Ao ocuparem tempo e espaço extraordinários do ponto de vista de seus agentes, tais festas desarticulam e articulam de forma criativa e surpreendente diversos elementos da vida social. Dentre eles, a autora destaca em especial a dimensão de um novo prisma da experiência vivida no plano ritual da "relação com o tempo e sua passagem" (:80). O bumbá, com sua natureza mítica, toma partido da temporalidade cíclica e tradicional, enquanto o desfile das escolas de samba, moderno em sua concepção linear do tempo, revolta-se contra a irreversibilidade de sua passagem, adensando o instante e fazendo uso de múltiplas linguagens superpostas (:98). O potencial analítico aqui reside no acesso ao centro moral e cognitivo das sociedades que os promovem.

A segunda parte do livro - "Às margens do Ipiranga: África na América" - trata de rituais ligados a religiões afro-brasileiras. É composta pelos textos de Adaílton Moreira, líder religioso que fala sobre a celebração do nascimento iniciático no candomblé; de Denise Zenícola, acerca da dança das iabás e de Zeca Ligiéro sobre as performances do Zé Pilintra. Os textos reunidos nessa parte trazem ao leitor três diferentes pontos de vista, mostrando as fronteiras dinâmicas dos lugares sociais dos analistas da performance. $O$ primeiro texto trata da performance do ponto de vista nativo, pois Adaílton é líder religioso, babaebé de uma comunidade de candomblé do Rio de Janeiro. Adaílton nos fala sobre o aprendizado continuado que envolve a iniciação ou o "nascimento" de um novo membro. Esse processo de preparação inclui diversos atores sociais: a comunidade, pessoas de outras casas, os orixás, de modo a expandir a experiência do nascimento individual em um processo de aprendizado compartilhado que afirma a construção performativa da comunidade como um todo. $O$ segundo texto que compõe essa parte é da bailarina e coreógrafa Denise Zenícola. A observação e vivência da autora acontecem no mesmo terreiro de Adaílton. Tendo sido iniciada, Denise se apropria de sua experiência corporal, para compreender os deslocamentos entre as qualidades gerais da dança das iabás. A autora indica que a prática de formas espetaculares de performances revela também a história de um corpo social e cultural, dialogando e permitindo a construção de um corpo mágico (:117). O ensaio do diretor de teatro e teatrólogo Zeca Ligiéro, por sua vez, destaca o jogo teatral da entidade da umbanda, o Zé Pelintra. Sua performance se realiza em uma zona de transição, entre o jogo e 
a diversão, entre o bem e o mal, entre valores terrenos e espirituais. A performance de Zé Pelintra toma partido de um lugar ambíguo, caracterizado pela dubiedade de comportamentos e de sentimentos despertados com quem com ele interaja. Entre o teatro e o ritual, em um continuum complementar (:124), como elabora Schechner, o Zé Pelintra performa e possibilita brincar com os pólos da vida social.

A terceira parte da coletânea se intitula "Catolicismo à brasileira". Contém o texto de Marcelo da Costa, que relaciona os temas da liturgia, controle e ação em Alceu Amoroso Lima; o de Jessie Jane de Sousa sobre Nossa Senhora de Aparecida e a sacralização do trabalho na Companhia Siderúrgica Nacional; e o artigo de John Dawsey sobre as margens dos rituais a partir do estudo do parque de diversões em Aparecida do Norte. Nesta terceira parte, as possibilidades de abordagem da performance do catolicismo ganham lentes distintas, ora a centralidade da trajetória individual de um intelectual, ora a da Igreja Católica como instituição aliada ao Estado; e também as margens da devoção popular. Por meio da análise da trajetória social do intelectual católico, Alceu de Amoroso Lima, Marcelo da Costa identifica uma performance de si mesmo, que o próprio Amoroso Lima descreveu por meio de sua "tripla devoção diária". Trata-se das três atividades com que iniciava seu dia: ida à missa, leitura do Breviário e escrita à filha enclausurada em abadia beneditina (:137). O historiador faz uso da noção dessas três atividades performáticas para identificar "elementos clássicos cristianizados - como a escrita de si, o exame de consciência diário, a meditação como exercício espiritual" de modo a realizar "uma particular visitação à tradição católica" (:146). Desse modo, Marcelo da Costa demonstra, por meio dos aspectos elaborados por Amoroso Lima, o acesso a elementos da tradição católica, em termos pessoais, e a possibilidade de uma flexibilidade na vivência de valores da Igreja e dos desafios do século, de modo mais amplo. No segundo artigo, Jessie Jane ilumina a ação da Igreja Católica, com o estímulo ao culto de Nossa Senhora da Aparecida por meio de estratégias de domínio moral das camadas sociais de trabalhadores, especificamente da Companhia Siderúrgica Nacional. Esta parte do livro encerra com o artigo do antropólogo John Dawsey sobre o culto à padroeira Nossa Senhora de Aparecida. O autor evidencia não apenas os aspectos da devoção identificados ao espaço central da igreja onde se encontra a santa, mas também as margens, na descida ao parque de diversões. Se a igreja marca o percurso do sagrado, o parque de diversões marca as margens, produzindo um duplo estranhamento e permitindo a transformação do ser e/ou da consciência - o estranhamento de um "eu" que não se transforma simplesmente num "outro" (:171).

Por fim, a quarta parte do livro - "Novas tendências: mídia e globalização religiosa" reúne o texto de Regina Abreu sobre o quarup; de Julio Cezar Benedito e João Gabriel Teixeira sobre as práticas religiosas neopentecostais no Distrito 
Federal e de Patricia Birman sobre as práticas new age. Os três artigos trazem em comum as relações entre tradições religiosas e atores sociais distintos em contato com as possibilidades de expansão por meio da globalização e da mídia. A antropóloga Regina Abreu descreve o encontro dos povos do Xingu, o quarup, ocorrido em julho de 2003, destacando nesse ano a homenagem inédita a um branco: Orlando Villas Boas. A autora identifica por meio das relações entre os diversos grupos que formavam a assistência do festival naquele ano - jornalistas, antropólogos, pesquisadores, autoridades governamentais e não governamentais - as novas possibilidades das interlocuções ali efetivadas ampliadas pela mídia. Como sintetiza a autora, "falar do quarup é falar da participação de cada um e de todos" (:190). O artigo de Julio Cezar Benedito e João Gabriel Teixeira tratam da apropriação de recursos performáticos nas práticas da Igreja Universal do Reino de Deus. Os autores problematizam os usos de símbolos ligados às práticas religiosas do catolicismo, dos umbandistas e dos místicos, bem como a inclusão de tais recursos em um circuito fortemente mercadológico orientado pelo marketing e por forte apelo popular. A antropóloga Patricia Birman segue o debate sobre a capacidade de ampliação que as experiências performáticas ganham nas práticas new age. Ao analisar eventos organizados na cidade do Rio de Janeiro, a autora percebe um modelo de globalização de tal fenômeno religioso (:237) que alcançou importantes platéias. Movimentos locais como a vigília "Um dia pela Terra" na ECO 92, o "Abraço à Candelária", e o evento "Dois minutos de silêncio" se constroem a partir de representações ligadas ao ideário multiculturalista de redemocratização e inclusão social, cujo alcance extrapola as fronteiras locais.

As quatro partes do livro encerram um painel complexo não apenas da variedade das manifestações festivas e religiosas no Brasil, mas também das possibilidades de vivenciá-las e de compreendê-las. A diversidade das abordagens realizadas reflete a imprecisão produtiva da noção de performance e também o interesse e a potencialidade teórico-analítica que alimentam os debates promovidos neste livro. O eixo norteador das discussões parece confirmar que o aspecto vivido da experiência é central nos estudos de performance. Neles, a participação ampla dos atores envolvidos, em que protagonismos são deslocados e o lugar corriqueiro das coisas ganha arranjos distintos, fornece novas perspectivas para todos aqueles que enfrentam o desafio de empreendê-los.

Renata de Sá Gonçalves (sarenata2005@yahoo.com.br) Bolsista CAPES/PRODOC no Programa de Pós-Graduação em Sociologia e Antropologia da Universidade Federal do Rio de Janeiro. 